\title{
Impact of livestock on a mosquito community (Diptera: Culicidae) in a Brazilian tropical dry forest
}

\author{
Cleandson Ferreira Santos ${ }^{[1]}$ and Magno Borges ${ }^{[1]}$
}

[1]. Laboratório de Ecologia e Controle Biológico de Insetos, Departamento de Biologia Geral, Universidade Estadual de Montes Claros, Montes Claros, Minas Gerais, Brasil.

\begin{abstract}
Introduction: This study evaluated the effects of cattle removal on the Culicidae mosquito community structure in a tropical dry forest in Brazil. Methods: Culicidae were collected during dry and wet seasons in cattle presence and absence between August 2008 and October 2010 and assessed using multivariate statistical models. Results: Cattle removal did not significantly alter Culicidae species richness and abundance. However, alterations were noted in Culicidae community composition. Conclusions: This is the first study to evaluate the impact of cattle removal on Culicidae community structure in Brazil and demonstrates the importance of assessing ecological parameters such as community species composition.
\end{abstract}

Keywords: Culicidae. Livestock. Community composition.

Livestock are a main driver of biodiversity loss in ecosystems, mainly through alterations of local habitat through deforestation, destruction of riparian areas, and wetland drainage ${ }^{(1)}$. The impact of livestock on biodiversity may also be related to the use of production animals as a resource by other organisms. Hematophagous insects can readily exploit domestic animals as hosts. Cattle herds serve as important blood sources and are among the main hosts for mosquitoes (Diptera: Culicidae).

Three non-mutually exclusive epidemiological scenarios of disease transmission by insect vectors can result from the introduction of livestock to an area: 1) reduction in number of feedings on the human population leading to a reduction in disease transmission; 2) an increase in the vector population as a result of the extra blood source and/or an increase in habitat availability to larvae, leading to an increase in the number of feedings per person; and 3) an increase in the risk of disease transmission because the introduced domestic animals serve as reservoirs for human diseases ${ }^{(2)}$. To circumvent negative impacts of vectors on human hosts coexisting with animals, zooprophylaxis, is a commonly used method. This practices is defined by World Health Organization as the use of wild or domestic animal that are not hosts of a particular disease as reservoirs to divert mosquito vectors from human hosts.

One disadvantage of adopting zooprophylactic practices is that raising several domestic animals may change environmental

Corresponding author: Cleandson Ferreira Santos. Laboratório de Ecologia e Controle Biológico de Insetos/Dept ${ }^{\circ}$ de Biologia Geral/UNIMONTES. Campus Universitário Professor Darcy Ribeiro, Vila Mauricéia, 39401-089 Montes Claros, Minas Gerais, Brasil.

Phone: 5538 3229-8192

e-mail: cfsbio@gmail.com

Received 22 January 2015

Accepted 31 March 2015 conditions and lead to the production of suitable breeding sites for mosquito larvae, increasing the mosquito populations in these regions and thus increasing the risk of mosquito-borne disease transmission and co-infection. In Brazil, a knowledge gap exists regarding the impact of livestock on Culicidae fauna. Most studies that have addressed the influence of cattle on Culicidae species were performed primarily to determine the feeding preferences of mosquito species. Thus, the aim of our study was to evaluate the effect of cattle removal on Culicidae community composition in a tropical dry forest in the northern region of Minas Gerais, Brazil. The following hypotheses were tested: I) cattle presence increases Culicidae species richness and abundance and II) cattle removal alters Culicidae community composition.

The study was performed in the Mata Seca State Park (Parque

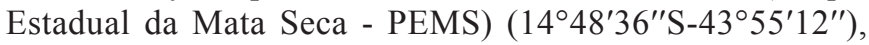
located in the Manga municipality; Northern Minas Gerais, Brazil (Figure 1). The region's climate is classified as tropical dry with a mean annual temperature of $24.4^{\circ} \mathrm{C}$ and rainfall of $871 \mathrm{~mm}^{(3)}$, characterized by a marked dry season in the winter, with seven months with rainfall levels lower than $60 \mathrm{~mm}$ and forests areas dominated by deciduous vegetation, with $90-95 \%$ leaf loss. The park was created through the expropriation of four farms with extensive cattle farming and plantations of common beans and corn in two pivots of 80 hectares each ${ }^{(3)}$. In 2008, this area still housed approximately 800 cattle that were removed in the second half of 2009, according to information obtained from the office of the Supervisory Agency of Farming in Minas Gerais [Instituto Mineiro de Agropecuária (IMA)].

Culicidae sampling was performed in three tropical dry forests fragments and one plot located in the gallery forest of a large pond (Lagoa da Prata) in different periods: August 2008 and March 2009 (dry and rainy seasons with the presence of cattle) and December 2009 and October 2010 


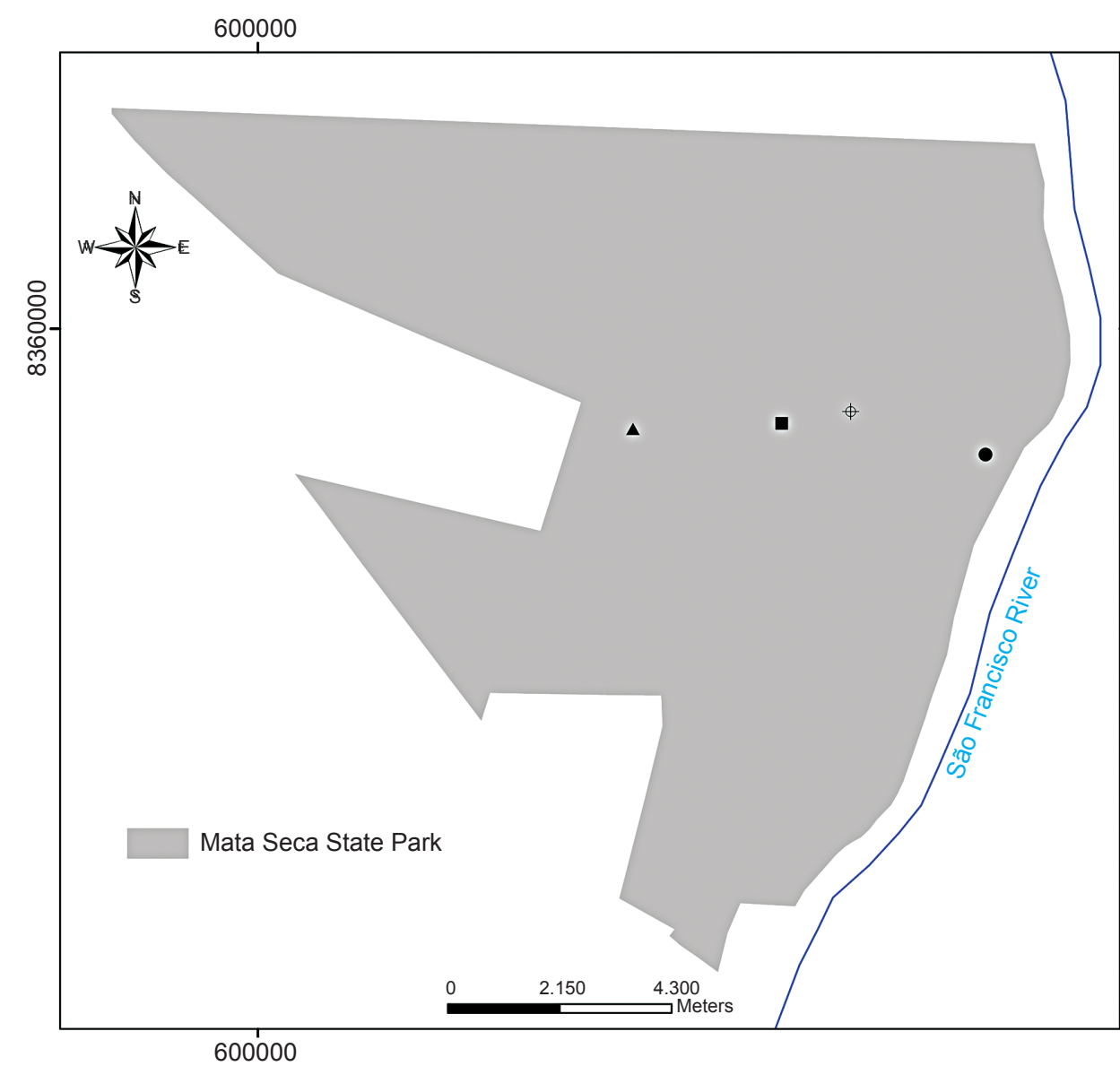

Mata Seca State Park Minas Gerais State, Brazil

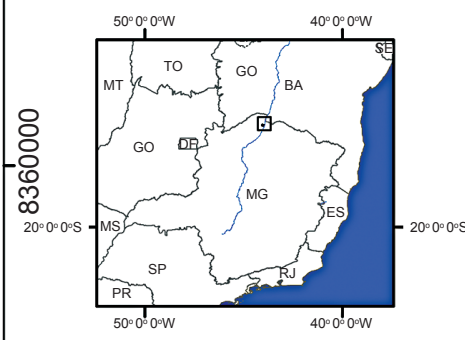

Sucessional Stages:

\ Early

- Intermediate

\$ Late

- Pond

Coordinate System UTM Zona 23 Datum SAD-69

Source: ICMBIO, 2010 IGAM, 2002 IBGE, 2005

Org: Clemente, C.M.S, 2013

FIGURE 1 - Map of Mata Seca State Park (PEMS), Minas Gerais, Brazil, highlighting the plots sampled in this study. PEMS: Parque Estadual da Mata Seca.

(rainy and dry seasons without cattle). Culicid collections were performed at dusk using one Shannon trap exposed for two hours per site for 8 nights ( 16 hours total) during each collection period. The mosquitoes were taxonomically identified using dichotomous keys ${ }^{(4)}$ and incorporated into the entomological collection of the Laboratory of Ecology and Biological Control of Insects at Montes Claros State University.

To identify the effect of the presence of cattle on Culicidae species richness and abundance, the data were fit to generalized linear models (GLMs). The significance of each variable was tested by an analysis of deviance using the chi-squared test. All of the GLMs underwent residual analyses to assess the adequacy of the error distributions. All analyses were performed with R 2.15 software $^{(5)}$.

To evaluate the effect of cattle removal on Culicidae community composition, non-metric multidimensional scaling (NMDS) was performed using the Bray-Curtis dissimilarity index. To test for differences in community composition between sampling periods (presence vs. absence of cattle), analysis of similarity (ANOSIM) was performed. Moreover, a similarity percentage analysis (SIMPER) was used to determine which species contributed the most to the formation of distinct groups (when cattle were present or absent). The analyses were performed with the PAST software ver. $2.17 \mathrm{c}^{(6)}$.

A total of 5,170 mosquitoes were collected in the presence ( $\mathrm{n}=2,045$ mosquitoes) or absence of cattle $(\mathrm{n}=3,125$ mosquitoes), and 21 and 27 species were represented, respectively (Table 1). The presence of cattle had no effect on of Culicidae richness $(p=0.531)$ or abundance $(p=0.521)$.

The Mansonini tribe represented $81.2 \%$ of mosquitoes collected (1,720 individuals during the period with cattle and 2,480 individuals after cattle removal). Mansonia titillans was the most abundant species sampled representing $(29.1 \%)$ of the total number of collected mosquitoes and 1,509 (60.8\%) of those collected after cattle removal. The species with the highest abundance during the period with cattle present was Coquillettidia nigricans, comprising 510 individuals (9.8\% of the total mosquitoes collected).

The NMDS analysis indicated a change in the culicid community: two distinct groups were observed, suggesting that cattle removal affects community composition (Figure 2). The analysis of similarity (ANOSIM) showed that 
TABLE 1 - Mosquito species of Mata Seca State Park, State of Minas Gerais, Brazil, collected at two different periods: with cattle (Aug 2008 and Mar 2009) and without cattle (Dec 2009 and Oct 2010).

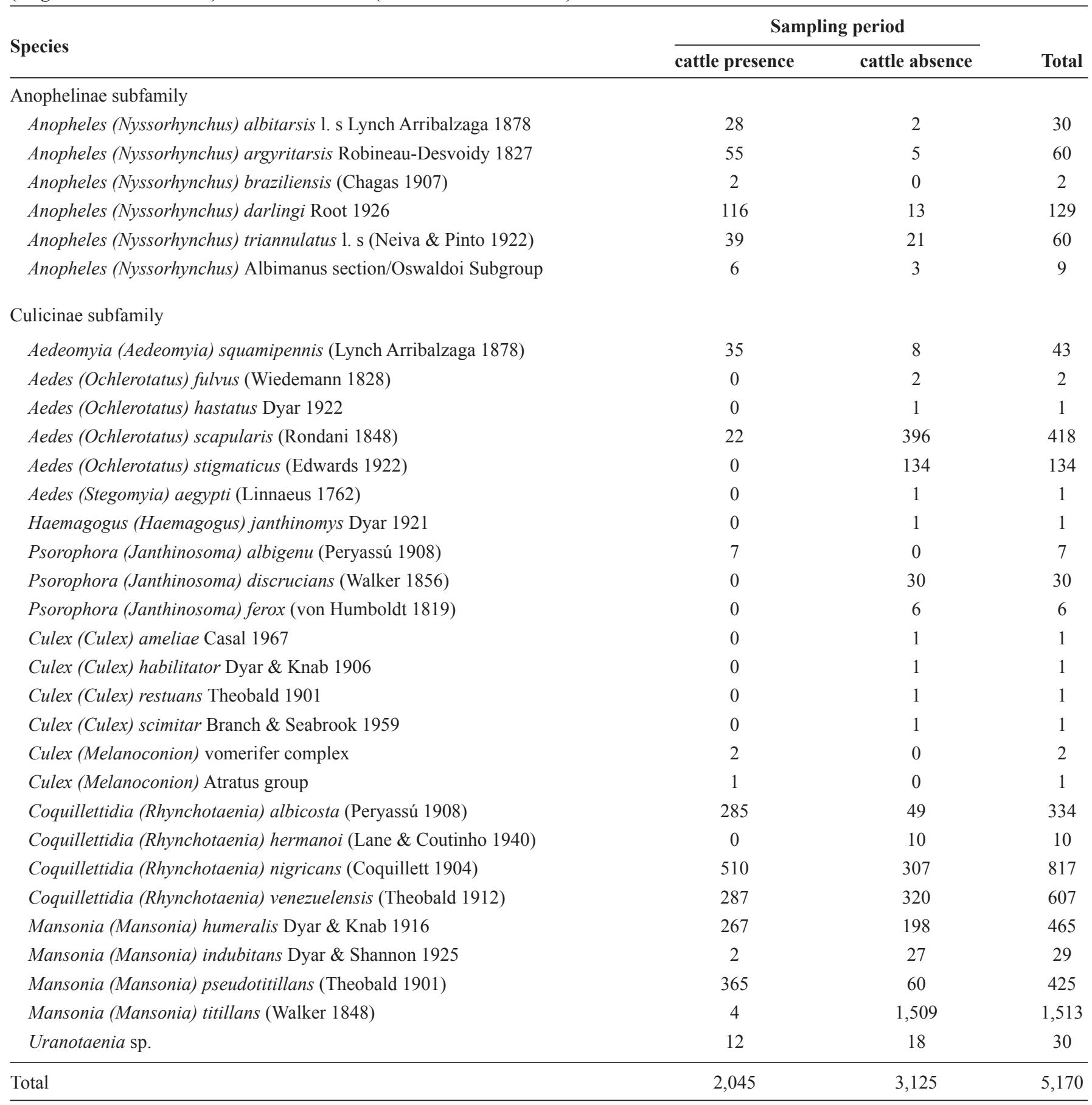

Culicidae community composition in PEMS differs significantly between sampling periods $(\mathrm{R}=0.4989 ; \mathrm{p}<0.01)$.

The SIMPER analysis showed that the species contributing most to the formation of clusters with or without cattle include Mansonia titillans, Mansonia humeralis, Mansonia pseudotitillans, Coquillettidia nigricans, and Coquillettidia venezuelensis, together comprising $71.6 \%$ of the two distinct groups reported by NMDS (Figure 2).
These results suggest that the presence of cattle results in changes in Culicidae community structure, without necessarily altering species richness and total abundance. Multivariate analytical approaches are rarely used in studies on Culicidae, despite the broad applications of understanding species composition and ecological community changes. The NMDS analysis has been used, however, to predict annual cycles of the composition of mosquitoes influenced by rainfall in Darwin, Australia ${ }^{(7)}$. 


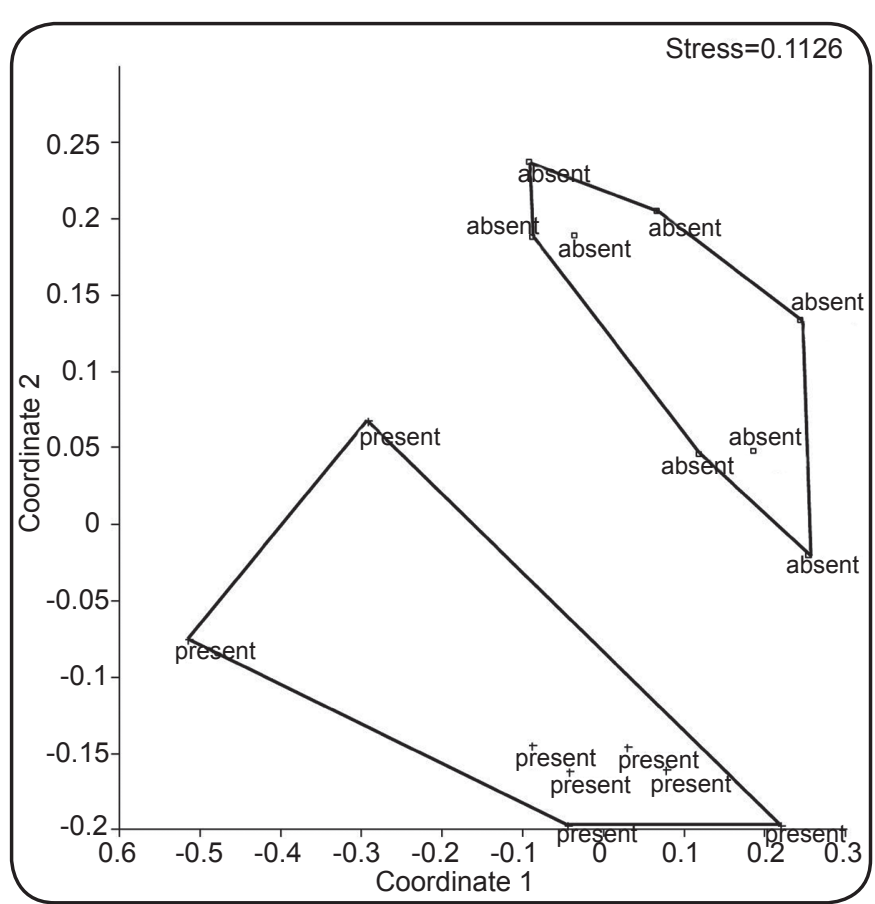

FIGURE 2 - Non-metric Multidimensional Scaling (NMDS) plot showing the separation of the mosquito communities of Mata Seca State Park (PEMS), Minas Gerais, Brazil. PEMS: Parque Estadual da Mata Seca.

The high abundance of mosquitoes of the Mansonini tribe may be explained by the presence of dense aquatic vegetation in Lagoa da Prata, which serves as a breeding site for these mosquitoes. Immature mosquitoes can attach to this aquatic vegetation through modified siphons for respiration and become dependent on these macrophytes for survival ${ }^{(4)}$.

Mansonini mosquitoes have been considered ornithophilic by other Brazilian authors, preferring to feed on avian species ${ }^{(8)}$. Cattle are large animals with few defensive behaviors and may have opportunistically shifted these insects to a hematophagic diet in cattle. Culex tarsalis can change their diet seasonally, feeding on mammals when their preferred hosts, herons and other aquatic birds, migrate to other locations ${ }^{(9)}$. Moreover, the increase in bird diversity and abundance after cattle removal from PEMS (unpublished data) may have contributed to the return of Ma. titillans to an ornithophilic diet. This hypothesis would need to be verified by longitudinal studies and the analysis of bloodmeals.

The choice of hosts for hematophagy may be driven by several factors, including the availability and defensive behavior of hosts, blood nutritional value, and the energy cost of digestion $^{(10)}$. Mosquitoes within a community depend primarily on host availability, and contact with specific hosts is influenced more by host presence/absence than by innate selection by the mosquitoes. Several studies have investigated the feeding preference of Culicidae, indicating that several mosquito species are more selective in host preference and feed on one or a few closely related species. Indeed, some hosts, including hoofstock (cattle and horses), other domestic animals, humans, and birds are preferred by certain mosquito species. Other mosquito species are not as discriminatory and select their hosts from among mammals, birds, and reptiles ${ }^{(11)}$.

Coquillettidia nigricans and Coquillettidia albicosta were more abundant when cattle were present, corroborating reports of a preference for large mammals by mosquitoes of this genus ${ }^{(12)}$. Among the Aedini mosquitoes, the most abundant species was Aedes scapularis, which was sampled in both collection periods but found to be especially prevalent in the absence of cattle. Ae. scapularis has received attention for its adaptation to environments modified by humans. The domiciliation of $A e$. scapularis in Brazil was documented in 1961, suggesting that this mosquito readily adapts to human-mediated environments ${ }^{(4)}$.

The results presented here suggest an association between species of the genus Anopheles and the presence of cattle. Anopheles albitarsis 1.s. typically co-occurs with cattle, reinforcing previous results that this anopheline has a strong tendency to perform hematophagy on large animals, such as cattle and horses ${ }^{(13)(14)}$.

The abundance of Anopheles darlingi co-occurring with cattle is nine times higher than its abundance without the host. This species is considered the most widely distributed anopheline in South America and is the main vector of Plasmodium spp. (the protozoan parasite that causes malaria in humans) in Brazil. Bloodmeal analysis of An. darlingi collected in resting habitats at three rural villages located in State of Amapá found that $57 \%$ of non-mixed bloodmeals are from cattle, while only $12 \%$ are from human, demonstrating that this species may be more eclectic in its food habits ${ }^{(15)}$.

Most of the literature regarding the effects of livestock on mosquito populations consists of paired studies comparing different areas with or without cattle near human dwellings, measuring the risk of acquiring a disease, in most cases malaria. The present study, although limited by the small number of samples, is the first in Brazil to characterize the effects of mosquito composition in the same area with and without cattle, and to demonstrate a change in Culicidae community structure in the absence of this important blood source. Furthermore, this study improves our understanding of the ecology of mosquito fauna in this semi-arid region with an important economic base on livestock and points out the risks and the need for surveillance to prevent possible disease outbreaks.

\section{ACKNOWLEDGMENTS}

The authors gratefully acknowledge the staff of the Instituto Estadual de Florestas for logistical support and for allowing us to conduct fieldwork at Mata Seca State Park (PEMS).

\section{CONFLICT OF INTEREST}

The authors declare that there is no conflict of interest. 


\section{FINANCIAL SUPPORT}

This work was funded in part by grants from Conselho Nacional de Desenvolvimento Científico e Tecnológico (CNPq - 563304/2010 3 and 562955/2010 0), Fundação de Amparo à Pesquisa de Minas Gerais (FAPEMIG CRA APQ 00001 11), and the Inter American Institute for Global Change Research (IAI CRN II 021).

\section{REFERENCES}

1. Steinfeld H, Gerber P, Wassenaar T, Castel V, Rosales M, Haan C. Livestock's long shadow - Environmental issues and options. Rome: Food and Agriculture Organization of the United Nations; 2006.

2. Service MW. Agricultural development and arthropod-borne diseases: a review. Rev Saude Publica 1991; 3:165-178.

3. Madeira BG, Espírito Santo MM, D'Angelo-Neto S, Nunes YRF, Sánchez Azofeifa GA, Fernandes GW, et al. Changes in tree and liana communities along a successional gradient in a tropical dry forest in south-eastern Brazil. Plant Ecol 2009; 201:291-304.

4. Forattini OP. Culicidologia Médica. São Paulo: EDUSP; 2002.

5. R Core Team. R: A language and environment for statistical computing. R Foundation for Statistical Computing, Vienna, Austria; 2013. (Cited 2015 January 22). Available at: http://www.r-project.org.

6. Hammer O, Harper DAT, Ryan PD. PAST: Paleontological statistics software package for education and data analysis. Palaeontol Electronica 2001; 4:1-9.
7. Franklin DC, Whelan PI. Tropical mosquito assemblages demonstrate 'textbook' annual cycles. PLoS One 2009; 4:e8296.

8. Silva JS, Alencar J, Costa JM, Seixas-Lorosa E, Guimarães AE. Feeding patterns of mosquitoes (Diptera: Culicidae) in six Brazilian environmental preservation areas. J Vector Ecol 2012; 37:342-350.

9. Thiemann TC, Brault AC, Ernest HB, Reisen WK. Development of a high-throughput microsphere-based molecular assay to identify 15 common bloodmeal hosts of Culex mosquitoes. Mol Ecol Resour 2012; 12:238-246.

10. Lyimo IN, Ferguson HM. Ecological and evolutionary determinants of host species choice in mosquito vectors. Trends Parasitol 2009; 25:189-196.

11. Tolle MA. Mosquito-borne diseases. Curr Probl Pediatr Adolesc Health Care 2009; 39:97-140.

12. Forattini OP, Gomes ADC, Natal D, Kakitani I, Marucci D. Preferências alimentares de mosquitos Culicidae no Vale do Ribeira, São Paulo, Brasil. Rev Saude Publica 1987; 21:171-187.

13. Lourenço-de-Oliveira R, Heyden R. Alguns aspectos da ecologia dos mosquitos (Diptera: Culicidae) de uma área planície (Granjas Calábria), em Jacarepaguá, Rio de Janeiro. IV. Preferências alimentares quanto ao hospedeiro e frequência domiciliar. Mem Inst Oswaldo Cruz 1986; 81:15-27.

14. Lucena D. Hábitos domiciliares do Anopheles tarsimaculatus Goeldi, 1905. Rev Bras Malariol D Trop 1950; 2:239-260.

15. Zimmerman RH, Galardo AKR, Lounibos LP, Arruda M, Wirtz R. Bloodmeal Hosts of Anopheles Species (Diptera: Culicidae) in a Malaria-Endemic Area of the Brazilian Amazon. J Med Entomol 2006; 43:947-956. 